\title{
An experimental investigation of detonation limits in hydrogen-oxygen-argon mixtures
}

\author{
Yuan $\mathrm{Gao}^{1 \dagger}$, Bo Zhang ${ }^{2}$, Hoi Dick Ng${ }^{3}$, John H.S. Lee ${ }^{1}$ \\ ${ }^{\dagger 1}$ Department of Mechanical Engineering, \\ McGill University, Montréal, Québec, H3A 2K6, Canada \\ ${ }^{2}$ State Environmental Protection Key Laboratory of Risk Assessment \\ And Control on Chemical Process \\ East China University of Science and Technology, Shanghai, 200237, China \\ ${ }^{3}$ Department of Mechanical and Industrial Engineering, \\ Concordia University, Montréal, Québec, H3G 1M8, Canada
}

\author{
${ }^{\dagger}$ Corresponding Author \\ E-mail: dutgaoyuan@gmail.com \\ Tel.: +15143986301 \\ Fax: +15143987365
}

Manuscript submitted to International Journal of Hydrogen Energy

August, 2015 


\begin{abstract}
The present paper reports the results of an experimental study of detonation limits for $\mathrm{H}_{2} / \mathrm{O}_{2} /$ Ar mixtures. Two stoichiometric mixtures $\left(2 \mathrm{H}_{2}+\mathrm{O}_{2}+3 \mathrm{Ar}\right.$ and $\left.2 \mathrm{H}_{2}+\mathrm{O}_{2}\right)$ in three different diameter round tubes $(D=1.8,4.6$ and $10.9 \mathrm{~mm})$ were tested. The choice of the mixture represents those considered as "stable" with a regular cellular pattern and "unstable" with an irregular cellular pattern. Detonation velocity was measured by ionization probes spaced at regular intervals along the small tubes. Consistent with previous findings, the present results show that well within the limits the detonation wave in hydrogen mixtures propagates at a steady velocity close to the theoretical Chapman-Jouguet (CJ) value. With decreasing initial pressure, the velocity deficit increases. It is found that the detonation velocity decreases with decreasing tube diameter, which is a result of the wall boundary layer effect being more prominent for smaller tubes. At the limiting pressure, the steady velocity deficit for both tested mixtures in three different diameter tubes is about $15-18 \%$. Velocity deficits were also estimated theoretically using the Fay model. For the stable mixture good agreement is found between the theoretical prediction and the experimental result of detonation velocity. For the unstable mixture, however, the theoretical prediction deviates from the experimental measurement. The latter thus suggests that, apart from losses due to the flow divergence caused by the boundary layer effect, instabilities are also significant for the detonation propagation and failure in unstable mixtures. Lastly, at the limits, the value of $D / \lambda$ is found to agree well with that for the onset of single-headed spin detonation. Thus, it can be concluded that the single-headed spin criterion can also be used for defining the detonation limits for hydrogen mixtures.
\end{abstract}

Keyword: Detonation limits; Hydrogen; Velocity deficits; Safety 


\section{Introduction}

The rapid growing worldwide energy needs and greenhouse gas emissions continue to pose great challenges for the existing energy infrastructures. To address these issues, hydrogen has long been proposed as an excellent alternative energy source to replace either gasoline and/or natural gas due to its unique properties, i.e., broad limits range of flammability [1], low ignition energy [2], lack of hydrocarbon and carbon dioxide in combustion products [3]. Indeed, the hydrogen usage is currently increasing and spreading out to many branches of industry including chemical production, metal refining, electronics manufacturing, vehicles and propulsion [4-6]. However, the aforementioned distinct properties of hydrogen may also be considered as disadvantages, and significant safety concerns are associated with hydrogen [7-10]. Because of its wide flammability limit and low ignition energy, a hydrogen cloud could be easily ignited once leakage occurs, generating a slow or fast deflagration, or even a detonation. Although a deflagration is generally the most probable mode of combustion, it could continuously accelerate and undergo an abrupt transition to a detonation under appropriate conditions depending on the concentration, initial pressure, and the confinements involved [11-15]. Potential risks concerning the occurrence of hydrogen detonation have to be clearly identified and taken into account while establishing safety standards, methodologies and regulations for engineering systems working with hydrogen.

One of the dynamic parameters of detonation wave is the detonability limit which is of significance both from a safety engineering as well as fundamental point of view. Detonation limits refer to the conditions outside of which a steady self-sustained propagation of a detonation wave is not possible [16]. The limit phenomenon is a consequence of adverse effect of boundary conditions on the propagation mechanism of a self-sustained detonation. Applying to the industry, detonation limit is equivalent to the conventional parameter of 
quenching distance or maximum experimental safe gap (MESG) for deflagration used commonly for safety assessment [14]. However, the mechanism of failure is not the same due to different physical processes that controlled their propagation [16]. It has been experimentally well-established that in small diameter tubes as the detonation limits are approached the detonation velocity decreases rapidly. The velocity deficit can be attributed to various effects such as the heat and momentum losses to tube walls, flow divergence caused by the boundary layer effect as well as the interference of tube walls with intrinsic instability of the cellular detonation front. Because of these complex interactions, no complete theory for the determination of detonation limits has yet been developed. In addition, near failure of the detonation, the velocity fluctuations become increasingly large, making the experimental measurement difficult to distinguish precisely the boundary between successful propagation and failure of the detonation wave [19-21].

In the past, a number of criteria has been proposed for which could determine the detonation limits, see $[16,25]$ for a comprehensive review. Among those is the $\lambda / 3$ rule. As the limits are approached, it is observed experimentally that the cellular detonation tends toward the lowest propagation mode of single-headed spin with $\lambda=\pi \cdot D$, where $\lambda$ denotes the detonation cell size and $D$ is the tube diameter. Hence, using the onset of single-headed spin detonation as the criterion for defining the detonation limits results in the proposition of the $\lambda / 3$ rule. Recently, this criterion is re-examined and found to be applicable for various hydrocarbon mixtures and over a wide range of tube diameters [18].

In the literature, relatively very few detailed study of detonation limits for hydrogen mixtures had been made. In this study, new experiments were performed to observe the detonation velocity deficit and limits for hydrogen mixtures in small tubes. Three small diameter round tubes were used to ensure propagation of detonation wave over long distances ranging from 275 to 1667 tube diameter. Detonation velocities were measured by ionization 
probes located along the small tube. Two types of mixtures including the "stable" $\left(2 \mathrm{H}_{2}+\mathrm{O}_{2}+3 \mathrm{Ar}\right)$ and "unstable" $\left(2 \mathrm{H}_{2}+\mathrm{O}_{2}\right)$ mixtures were tested. For a stable mixture highly diluted with argon, the detonation wave generally has a very regular cellular structure; whereas for unstable mixtures, the detonation front is characterized by an irregular cellular pattern [26]. The experimentally measured velocity deficit is also compared with the theoretical prediction using the Fay model, which is essentially based on the loss due to the flow divergence caused by the effect of negative displacement thickness of the wall boundary layer. Using the present results, this study further establishes the applicability of the onset of single-headed spin or the $\lambda / 3$ rule as a criterion to be defined for detonation limits for hydrogen mixtures [18-20, 27-30].

\section{Experimental details}

The experimental apparatus consists of a driver section tube attached to the smaller diameter test section tube, as shown in Fig. 1. The driver section has a 25.4-mm inner diameter and 1500-mm length. Three different diameter test sections, $D=1.8,4.6$ and $10.9 \mathrm{~mm}$, were used in the present study with total tube length $L=3000 \mathrm{~mm}, 3000 \mathrm{~mm}, 3000 \mathrm{~mm}$ and thickness $T$ $=0.7 \mathrm{~mm}, 0.9 \mathrm{~mm}, 0.9 \mathrm{~mm}$, respectively. Equivalently, this gives a $L / D$ of about 275,652 and 1667, respectively. Each test section tube protruded some distance into the driver section in order to mitigate the effect of wave reflection from the flange at the driver end (see Fig. 1). A spark plug was connected to the ignition system in the driver section to generate a high energy spark as in our previous studies [18, 23, 24, 31-33]. A short length of Shchelkin spiral was also inserted just downstream of the spark plug to promote detonation formation.

Two combustible mixtures of $2 \mathrm{H}_{2}+\mathrm{O}_{2}+3 \mathrm{Ar}$ and $2 \mathrm{H}_{2}+\mathrm{O}_{2}$ were tested in the present study. The argon-diluted mixture gives a stable detonation with regular cellular pattern while the undiluted mixture is usually characterized by an irregular cellular pattern [26]. The explosive mixtures were prepared via partial pressure method in a separated gas bottle and were 
allowed to mix by diffusion for at least 24 h to ensure the homogeneity prior to be used. An Omega model PX309-030AI pressure transducer $(0-206 \mathrm{kPa})$ with an accuracy of $\pm 0.25 \%$ full scale was used to monitor the initial pressure in the detonation tube. The digital meter was calibrated to display the minimum pressure reading of $0.01 \mathrm{kPa}$. Two pressure transducers (Model: PCB 113A24) were mounted on the driver section that were spaced 750 $\mathrm{mm}$ and $1250 \mathrm{~mm}$ from the ignition plug in order to check that a Chapman-Jouguet (CJ) detonation was obtained before entering the test section tube. Velocity measurement in test section tube was made by three regularly spaced $(1500 \mathrm{~mm})$ ionization probes. Swagelok tube fitting was used to connect the ionization probe with the test section tube. For example, Fig. 2 shows an enlarged view of the ionization probes connection for the $1.8-\mathrm{mm}$ test section tube. Care was exercised to connect smoothly the tube with Swagelok tube fitting in order to avoid any influence of the joint on the flow. Note all CJ detonation velocities were computed using NASA-CEA program [34].

\section{Results and discussion}

In the present study, the detonation limit for a given mixture and tube diameter was obtained by progressively decreasing the initial pressure. Typical trajectories of detonation wave propagating in round tube under different initial pressures are shown in Fig. 3 for the case with the $2 \mathrm{H}_{2}+\mathrm{O}_{2}+3 \mathrm{Ar}$ mixture and $10.9-\mathrm{mm}$ round tube. The $x$-axis represents the wave propagation distance in the test section tube. The $y$-axis is the time of arrival of the reactive wave at the corresponding position. By measuring the slope of the ionization probe signals as given in the trajectories, detonation velocity can be determined. It can be observed that after entering the round tube, a self-sustained detonation wave was maintained when the initial pressure is higher than the limiting value. With decreasing initial pressure, the detonation velocity decreases continuously. At the limiting pressure $\left(P_{0}=8 \mathrm{kPa}\right)$, the detonation wave begins to fail after a short distance of travel (of about $\mathrm{X} / D=60$ ) in the round tube. 
From the trajectory plots, the steady detonation velocities can be determined for each experimental condition. It is worth noting that due to the limited number of ionization probes used in the present experiment, the local velocity is not resolved and hence, the velocity reported in this paper should be considered as an averaged global velocity when a steady value can still be extracted in the $x$ - $t$ diagram. For comparison, the theoretical predictions of the detonation velocity using the Fay model [35] are also computed in this work. The Fay model is based on the displacement effect caused by the wall boundary layer which leads to a flow divergence and hence, a wave curvature. The velocity deficit due to the boundary layer becomes identical to that caused by a curved detonation front. A steady detonation is not possible or fails when the curvature exceeds a certain critical value, i.e., the velocity deficit reaches to the maximum value. Using Fay's theory, an expression for the velocity deficit, $\Delta V_{\mathrm{m}}$, can be derived from the conservation equations of a quasi-one-dimensional flow [16, 35 , 36]:

$$
\Delta V_{m}=\frac{\Delta V}{V_{C J}}=\frac{V_{C J}-V}{V_{C J}}=1-\left[\frac{(1-v)^{2}}{(1-v)^{2}+\gamma^{2}\left(2 v-v^{2}\right)}\right]^{1 / 2}
$$

where $v=\xi /|(1+\gamma)(1+\xi)|$, $\xi$ is the coefficient factor of the steam tube area divergence, $\gamma$ is the ratio of specific heats under the Chapman-Jouguet $(\mathrm{CJ})$ condition. $V_{\mathrm{CJ}}$ and $V$ denote the theoretical CJ velocity and the detonation velocity observed in a round tube of diameter $D$. The area divergence can be estimated in term of the boundary layer displacement thickness $\delta^{*}$ as follows:

$$
\xi=\frac{A_{2}}{A_{1}}-1=\frac{\pi\left(\frac{D}{2}+\delta^{*}\right)^{2}}{\pi\left(\frac{D}{2}\right)^{2}}-1 \approx \frac{4 \delta^{*}}{D}
$$

where $\delta^{*}$ is the displacement thickness of the boundary layer. For smooth round tubes, the boundary layer displacement thickness has been determined experimentally in shock tube by 
Gooderum [37] as:

$$
\delta^{*}=0.22 x^{0.8}\left(\frac{\mu_{e}}{\rho_{1} V_{C J}}\right)^{0.2}
$$

where $x$ is the distance from the shock front, $\mu_{\mathrm{e}}$ is the viscosity of the hot gas, $\rho$ is the initial gas density ahead of the shock front.

To compute the velocity deficit for a given mixture and tube diameter using the Fay model, the reaction zone thickness has to be approximated. Since real detonations are unstable, the detonation cell length could serve as an appropriate length scale to characterize the reaction zone thickness of a cellular detonation. As found in [36], when $x$ is equal to one detonation cell length $L$, the calculated velocity deficit has a good agreement with the experimental data. In the present analysis, this relation of $x=L$ was also employed to determine the velocity deficit. The detonation cell length was obtained from the relation $L=1.67 \lambda$ proposed by Edwards [38]. The cell size for $2 \mathrm{H}_{2}+\mathrm{O}_{2}+3 \mathrm{Ar}$ mixture was measured experimentally in this work. For the undiluted $2 \mathrm{H}_{2}+\mathrm{O}_{2}$ mixture, the cell size data were obtained from [39]. The correlations of these data are shown in Table 1. Using the Fay model, both the theoretically predicted and experimentally measured detonation velocities, normalized with the CJ value as a function of initial pressure in different diameter tubes are shown in Figs. 4 and 5 for the two mixtures tested, i.e., $2 \mathrm{H}_{2}+\mathrm{O}_{2}+3 \mathrm{Ar}$ and $2 \mathrm{H}_{2}+\mathrm{O}_{2}$, respectively.

For the results of the stable $2 \mathrm{H}_{2}+\mathrm{O}_{2}+3 \mathrm{Ar}$ mixture shown in Fig. 4, well within the limits, detonation velocities are observed to be close to the theoretical CJ value. By decreasing the initial pressure, the velocity deficit increases. Also, for a given initial pressure the velocity deficit increases with decreasing tube diameter. For instance, at $P_{0}=40 \mathrm{kPa}$, the detonation velocity deficits for $2 \mathrm{H}_{2}+\mathrm{O}_{2}+3 \mathrm{Ar}$ mixture in $D=10.9 \mathrm{~mm}, 4.6 \mathrm{~mm}$ and $1.8 \mathrm{~mm}$ are $3 \%$ $\left(0.97 V_{\mathrm{CJ}}\right), 6 \%\left(0.94 V_{\mathrm{CJ}}\right)$ and $15 \%\left(0.85 V_{\mathrm{CJ}}\right)$, respectively. In the smallest diameter tube $(D=$ $1.8 \mathrm{~mm}$ ) the boundary layer is becoming comparable to the diameter scale and its effect 
would be more prominent than in the larger diameter tubes $(D=4.6 \mathrm{~mm}, D=10.9 \mathrm{~mm})$. As the detonation limits are approached, the velocity deficits reach to the maximum values. For $2 \mathrm{H}_{2}+\mathrm{O}_{2}+3 \mathrm{Ar}$ mixture the maximum velocity deficits in three different diameter tubes are about $18 \%$ which agree well with the result published in [40, 41]. For the stable mixture of $2 \mathrm{H}_{2}+\mathrm{O}_{2}+3 \mathrm{Ar}$ characterized by a regular cellular structure, it can be seen that the experimentally measured detonation velocities agree very well with the computed theoretical results based on the Fay model. Previous studies [16, 31, 40, 42] argue that for stable mixtures the reaction zone has a piecewise laminar structure as postulated in the ideal ZND model and the failure of detonation wave is due to the flow divergence caused by the boundary layer. Therefore, Fay's theory based on the quasi-steady ZND model could give a reasonable prediction of velocity deficits for stable mixtures as shown in the present results.

For the unstable $2 \mathrm{H}_{2}+\mathrm{O}_{2}$ mixture, again well within the limits, detonation velocities are close to the theoretical CJ values with a few percent of velocity deficits. Also, the velocity deficit increases with decreasing initial pressure and tube diameter. For the $2 \mathrm{H}_{2}+\mathrm{O}_{2}$ mixture in all different diameter tubes, the velocity drops to about $0.85 V_{\mathrm{CJ}}$ before failure. By comparing the experimental detonation velocity with the theoretical prediction using the Fay model, it can be seen that the prediction results deviate more from the experimental values. This can be explained perhaps by the fact that for unstable mixtures the detonation velocity deficit is less influenced by the boundary layer effect because the propagation mechanism is dominated by instability in the detonation structure, which is not accounted in Fay's theory. Hence, the lack of the instability mechanism in the Fay model leads to an inappropriate prediction of detonation velocity.

It becomes clear that the propagation of detonation wave in tubes depends on both the initial condition (e.g., composition or sensitivity of the mixture) and boundary condition (e.g., tube diameter) [16]. Detonation cell size, $\lambda$, is a characteristic length scale of detonation 
cellular structure which could represent the sensitivity of the explosive mixture. Meanwhile, the tube diameter $D$ represents the physical length scale of the wall boundary that determines the detonation limit for a given mixture at a given initial pressure. Therefore, $D / \lambda$ appears to be an appropriate parameter representing the relative role of the tube geometry to the chemical sensitivity of the explosive mixture. The variation of $D / \lambda$ versus $V / V_{\mathrm{CJ}}$ for $2 \mathrm{H}_{2}+\mathrm{O}_{2}$ $+3 \mathrm{Ar}$ and $2 \mathrm{H}_{2}+\mathrm{O}_{2}$ in different diameter round tubes are shown in Figs. 6 and 7. It can be seen that the results for all tested tube diameters of $1.8 \mathrm{~mm}, 4.6 \mathrm{~mm}$ and $10.9 \mathrm{~mm}$ lie on a single curve indicating that $D / \lambda$ provides indeed an appropriate dimensionless parameter to characterize the detonation propagation. At the limits, $D / \lambda$ reaches to the minimum value below which the detonation wave fails, thus defining the detonation limits. It is well established that for conditions toward the limits, a single-headed spin detonation eventually occurs which represents the lowest unstable mode of the detonation propagation $[16,43]$. Under this propagation mode, the scale of the frontal instability of single-headed spin is the same order as the tube diameter $(\lambda=\pi \cdot D)$. In fact, the onset of single-headed spin detonation, or so-called the $\lambda / 3$ rule, was used as the criterion for the detonation limits [18-20, 27-30]. For comparison, the theoretical $D / \lambda$ for the onset of single-headed spin detonation is also given in Figs. 6 and 7 (dashed dot line). The critical values of $D / \lambda$ for detonation limits in different round tubes obtained from experiments are also tabulated in Table 2. From these results, it appears that the critical $D / \lambda$ defining the detonation limit for both stable and unstable mixtures are in good agreement with the single-headed spin criterion $D / \lambda \approx 1 / \pi=$ 0.318. Hence, the results in the present investigation confirm that the onset of single-headed spin detonation is at least a reasonable criterion which could also be used to define the limiting condition for stable propagation of hydrogen-oxygen-argon detonation wave in round tubes.

\section{Concluding remarks}


In this experimental study, a detailed investigation of propagation limits of detonations in hydrogen-oxygen-argon mixtures in three different diameter tubes is carried out. Overall, the behavior of the detonation velocity deficit for hydrogen-oxygen-argon mixtures in small diameter round tubes is found similar to those observed in previous findings using various hydrocarbon mixtures [18]. Away from the limits, the detonation wave propagates at a steady velocity with a small percent of velocity deficit. With decreasing initial pressure for a given mixture, the detonation velocity decreases gradually. The detonation velocity is also found to decrease with decreasing tube diameter due to the wall boundary layer effect being more prominent for small diameter tube. In general, the range of detonation velocity when limits are approached changes from about $0.82 V_{\mathrm{CJ}}<V<V_{\mathrm{CJ}}$.

Using Fay's model which accounts the loss due to the flow divergence caused by the effect of boundary layer, the velocity deficit can be estimated theoretically. It is found that the prediction values of detonation velocity using the Fay model agree well with the experimental results for the stable mixture. For the unstable hydrogen-oxygen mixture without argon dilution the theoretical results deviate from the experimental measurement. The latter hence suggests that the instabilities play important role in the propagation and failure for unstable mixtures, which is not taken into account in the Fay's model.

Lastly, it is shown that the ratio of $D / \lambda$ provides also a suitable parameter to define the detonation limits for hydrogen-oxygen-argon mixtures. At the limits, for both hydrogen-oxygen mixtures with (stable) and without argon dilution (unstable), the values of $D / \lambda$ in all three small diameter round tubes agree well with the theoretical value of $1 / 3$ corresponding to the onset of single-headed spin criterion. Therefore, for safety assessment the single-headed spin criterion also serves well as an appropriate prediction of the detonation limits for hydrogen-oxygen mixtures.

\section{Acknowledgement}


This work is supported by the Natural Sciences and Engineering Research Council of Canada (NSERC).

\section{References}

[1] Kuznetsov M, Kobelt S, Grune J, and Jordan T. Flammability limits and laminar flame speed of hydrogen-air mixtures at sub-atmospheric pressures. Int J Hydrogen Energ 2012; 37: 17580-17588.

[2] Ono R, Nifuku M, Fujiwara S, Horiguchi S, and Oda T. Minimum ignition energy of hydrogen-air mixture: Effects of humidity and spark duration. J Electrostat 2007; 65: 87-93.

[3] Mohammadi A, Shioji M, Nakai Y, Ishikura W, and Tabo E. Performance and combustion characteristics of a direct injection si hydrogen engine. Int J Hydrogen Energ 2007; 32: 296-304.

[4] Dunn S. Hydrogen futures: Toward a sustainable energy system. Int J Hydrogen Energ 2002; 27: 235-264.

[5] Midilli A, Ay M, Dincer I, and Rosen MA. On hydrogen and hydrogen energy strategies: I: Current status and needs. Renew Sust Energ Rev 2005; 9: 255-271.

[6] Penner SS. Steps toward the hydrogen economy. Energy 2006; 31: 33-43.

[7] Fischer M. Safety aspects of hydrogen combustion in hydrogen energy systems. Int J Hydrogen Energ 1986; 11: 593-601.

[8] Petukhov VA, Naboko IM, and Fortov VE. Explosion hazard of hydrogen-air mixtures in the large volumes. Int J Hydrogen Energ 2009; 34: 5924-5931.

[9] Rigas F and Sklavounos S. Evaluation of hazards associated with hydrogen storage facilities. Int J Hydrogen Energ 2005; 30: 1501-1510.

[10] Gerboni R and Salvador E. Hydrogen transportation systems: Elements of risk analysis. Energy 2009; 34: 2223-2229. 
[11] Bédard-Tremblay L, Fang L, Melguizo-Gavilanes J, Bauwens L, Finstad PHE, Cheng Z, et al. Simulation of detonation after an accidental hydrogen release in enclosed environments. Int J Hydrogen Energ 2009; 34: 5894-5901.

[12] Bychkov V, Akkerman VY, Fru G, Petchenko A, and Eriksson L-E. Flame acceleration in the early stages of burning in tubes. Combust Flame 2007; 150: 263-276.

[13] Ciccarelli G and Dorofeev S. Flame acceleration and transition to detonation in ducts. Prog Energ Combust 2008; 34: 499-550.

[14] $\mathrm{Ng} \mathrm{HD}, \mathrm{Ju} \mathrm{Y}$, and Lee JHS. Assessment of detonation hazards in high-pressure hydrogen storage from chemical sensitivity analysis. Int J Hydrogen Energ 2007; 32: 93-99.

[15] Teodorczyk A, Drobniak P, and Dabkowski A. Fast turbulent deflagration and ddt of hydrogen-air mixtures in small obstructed channel. Int J Hydrogen Energ 2009; 34: 5887-5893.

[16] Lee JHS. The detonation phenomenon. Cambridge University Press; 2008.

[17] Britton LG. Using maximum experimental safe gap to select flame arresters. Process Saf Prog 2000; 19(3): 140-145.

[18] Gao Y, Ng HD, and Lee JHS. Minimum tube diameters for steady propagation of gaseous detonations. Shock Waves 2014; 24: 447-454.

[19] Dupré G, Knystautas R, and Lee JHS. Near-limit propagation of detonation in tubes. AIAA, Prog Astronaut Aeronaut 1986; 106: 144-259.

[20] Dupré G, Joannon J, Knystautas R, and Lee JHS. Unstable detonations in the near-limit regime in tubes. Symp (Int) Combust 1991; 23: 1813-1820.

[21] Lee JJ, Dupré G, Knystautas R and Lee JH. Doppler interferometry study of unstable detonations. Shock Waves 1995; 5: 175-181.

[22] Haloua F, Brouillette M, Lienhart V and Dupré G. Characteristics of unstable 
detonations near extinction limits. Combust Flame 2000; 122(4): 422-438.

[23] Gao Y, Lee JHS, and Ng HD. Velocity fluctuation near the detonation limits. Combust Flame 2014; 161: 2982-2990.

[24] Gao Y, Ng HD, and Lee JHS. Experimental characterization of galloping detonations in unstable mixtures. Combust Flame 2015; 162: 2405-2413.

[25] Camargo A, Ng HD, Chao J and Lee JHS. Propagation of near-limit gaseous detonations in small diameter tubes. Shock Waves 2010; 20(6): 499-508.

[26] Ng HD and Zhang F, Detonation instability, in: Shock waves science and technology library, vol. 6, F. Zhang, Editor. 2012, Springer Berlin Heidelberg. p. 107-212.

[27] Dove JE and Wagner HG. A photographic investigation of the mechanism of spinning detonation. Symp (Int) Combust 1961; 8: 589-600.

[28] Moen I, Sulmistras A, Thomas G, Bjerketvedt D, and Thibault P. Influence of cellular regularity on the behavior of gaseous detonations. Dynam Expl 1986; 220-243.

[29] Fischer J, Liebner C, Hieronymus $\mathrm{H}$ and Klemm E. Maximum safe diameters of microcapillaries for a stoichiometric ethene/oxygen mixture. Chem Eng Sci 2009; 64: 2951- 2956.

[30] Kitano S, Fukao M, Susa A, Tsuboi N, Hayashi AK, and Koshi M. Spinning detonation and velocity deficit in small diameter tubes. Proc Combust Inst 2009; 32: 2355-2362.

[31] Zhang B, Kamenskihs V, Ng HD, and Lee JHS. Direct blast initiation of spherical gaseous detonations in highly argon diluted mixtures. Proc Combust Inst 2011; 33: $2265-2271$.

[32] Zhang B, Ng HD, and Lee JHS. The critical tube diameter and critical energy for direct initiation of detonation in C2H2/N2O/ar mixtures. Combust Flame 2012; 159: 2944-2953.

[33] Zhang B, Ng HD, Mével R, and Lee JHS. Critical energy for direct initiation of 
spherical detonations in h2/n2o/ar mixtures. Int J Hydrogen Energ 2011; 36: 5707-5716.

[34] Mcbride BJ and Gordon S. Computer program for calculation of complex chemical equilibrium compositions and applications: Ii. Users manual and program description. NASA reference publication 1996; 1311: 84-85.

[35] Fay JA. Two-dimensional gaseous detonations: Velocity deficit. Phys Fluids 1959; 2: 283-289.

[36] Murray S and Lee JHS. The influence of physical boundaries on gaseous detonation waves. Prog Astronaut Aeronaut 1986; 106: 329-355.

[37] Gooderum PB. An experimental study of the turbulent boundary layer on a shock-tube wall. NACA Tech Note; 1958.

[38] Edwards D, Jones A, and Phillips D. The location of the Chapman-Jouguet surface in a multiheaded detonation wave. J Phys D Appl Phys 1976; 9: 1331.

[39] Denisov YN and Troshin YK. Structure of gaseous detonation in tubes. Sov Phys Tech Phys 1960; 5: 419-431.

[40] Chao J, Ng HD, and Lee JHS. Detonability limits in thin annular channels. Proc Combust Inst 2009; 32: 2349-2354.

[41] Ishii K and Monwar M. Detonation propagation with velocity deficits in narrow channels. Proc Combust Inst 2011; 33: 2359-2366.

[42] Radulescu MI, Ng HD, Lee JHS, and Varatharajan B. The effect of argon dilution on the stability of acetylene/oxygen detonations. Proc Combust Inst 2002; 29: 2825-2831.

[43] Lee JHS. Dynamic parameters of gaseous detonations. Annu Rev Fluid Mech 1984; 16: 311-336. 


\section{Table captions}

Table 1. Cell size correlations for mixtures as a function of initial pressure given by $\lambda[\mathrm{mm}]=$ $C\left(P_{0}[\mathrm{kPa}]\right)^{-\mathrm{n}}$

Table 2 Limiting pressure, cell size and $D / \lambda$ for $\mathrm{H}_{2}-\mathrm{O}_{2}$-Ar mixtures in different diameter round tubes

Table 1 Cell size correlations for mixtures as a function of initial pressure given by $\lambda[\mathrm{mm}]=$ $C\left(P_{0}[\mathrm{kPa}]\right)^{-\mathrm{n}}$

\begin{tabular}{lll}
\hline Mixture & $\mathrm{C}$ & $\mathrm{n}$ \\
\hline $2 \mathrm{H}_{2}+\mathrm{O}_{2}+3 \mathrm{Ar}$ & 964.7 & 1.372 \\
$2 \mathrm{H}_{2}+\mathrm{O}_{2}[36]$ & 187.8 & 0.79 \\
\hline
\end{tabular}

Table 2 Limiting pressure, cell size and $D / \lambda$ for $\mathrm{H}_{2}-\mathrm{O}_{2}-\mathrm{Ar}$ mixtures in different diameter round tubes

\begin{tabular}{lcccc}
\hline \multirow{2}{*}{ Mixture } & $\begin{array}{c}\text { Tube diameter: } \\
D(\mathrm{~mm})\end{array}$ & $\begin{array}{c}\text { Limiting Pressure: } \\
P(\mathrm{kPa})\end{array}$ & $\begin{array}{c}\text { Cell size: } \\
\lambda(\mathrm{mm})\end{array}$ & \multirow{2}{*}{$\mathrm{N} / \lambda$} \\
\hline \multirow{2}{*}{$2 \mathrm{H}_{2}+\mathrm{O}_{2}+3 \mathrm{Ar}$} & 1.8 & 35 & 66.8 & 0.25 \\
& 4.6 & 16 & 21.5 & 0.21 \\
& 10.9 & 7 & 7.3 & 0.16 \\
\cline { 2 - 5 } $2 \mathrm{H}_{2}+\mathrm{O}_{2}$ & 1.8 & 90 & 5.4 & 0.33 \\
& 4.6 & 35 & 11.4 & 0.40 \\
& 10.9 & 8 & 36.6 & 0.29 \\
\hline
\end{tabular}




\section{Figures captions}

Fig. 1. A schematic of the experimental apparatus

Fig. 2. An enlarged view of a 1.8-mm diameter tube ionization probe station

Fig. 3. Typical trajectories of a self-propagating detonation and detonation failure in the 10.9-mm diameter tube for the $2 \mathrm{H}_{2}+\mathrm{O}_{2}+3 \mathrm{Ar}$ mixture

Fig. 4. Detonation velocities normalized with the theoretical CJ value as a function of initial pressure in different diameter tubes for the $2 \mathrm{H}_{2}+\mathrm{O}_{2}+3 \mathrm{Ar}$ mixture

Fig. 5. Detonation velocities normalized with the theoretical CJ value as a function of initial pressure in different diameter tubes for the $2 \mathrm{H}_{2}+\mathrm{O}_{2}$ mixture

Fig. 6. Variation of $D / \lambda$ versus $V / V_{\mathrm{CJ}}$ for the $2 \mathrm{H}_{2}+\mathrm{O}_{2}+3 \mathrm{Ar}$ mixture

Fig. 7. Variation of $D / \lambda$ versus $V / V_{\mathrm{CJ}}$ for the $2 \mathrm{H}_{2}+\mathrm{O}_{2}$ mixture 


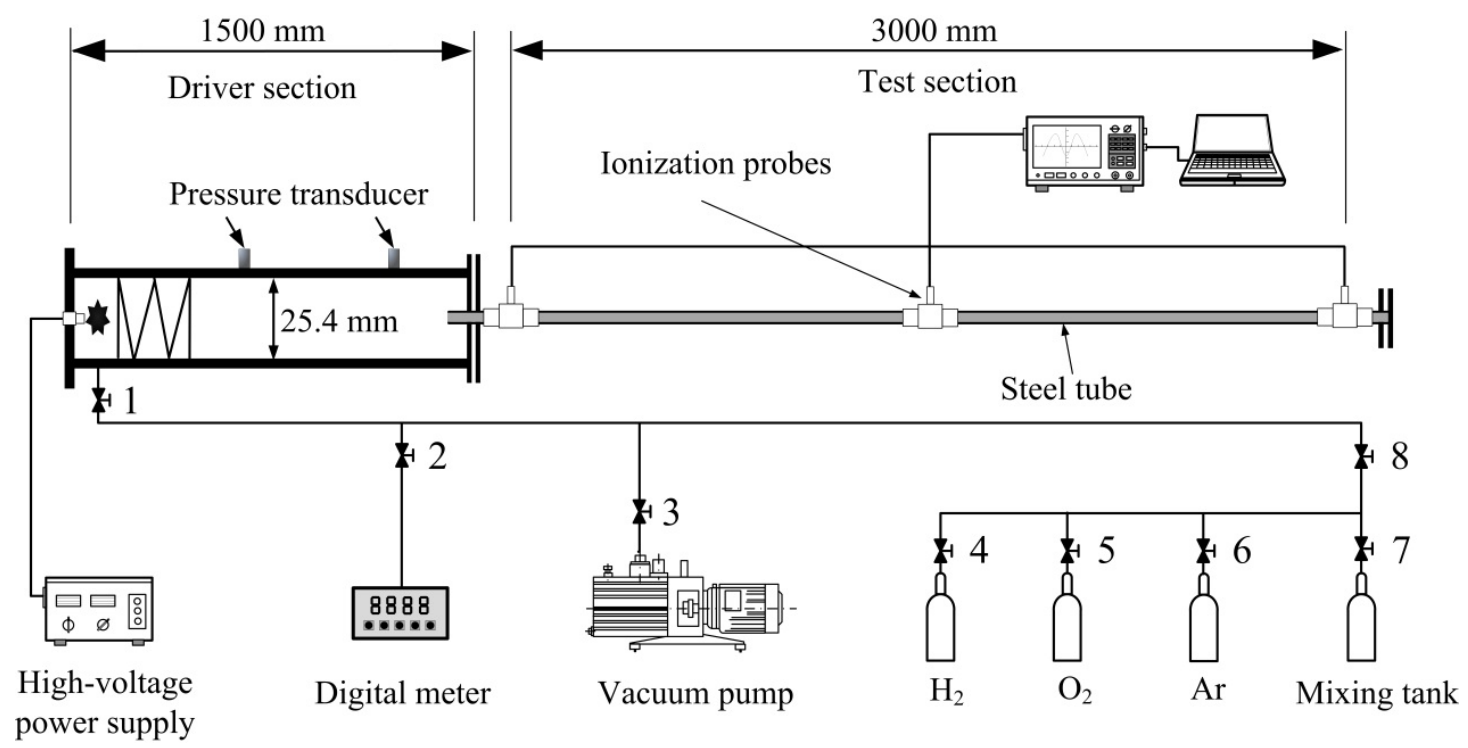

Fig. 1 




Fig. 2 




Fig. 3 


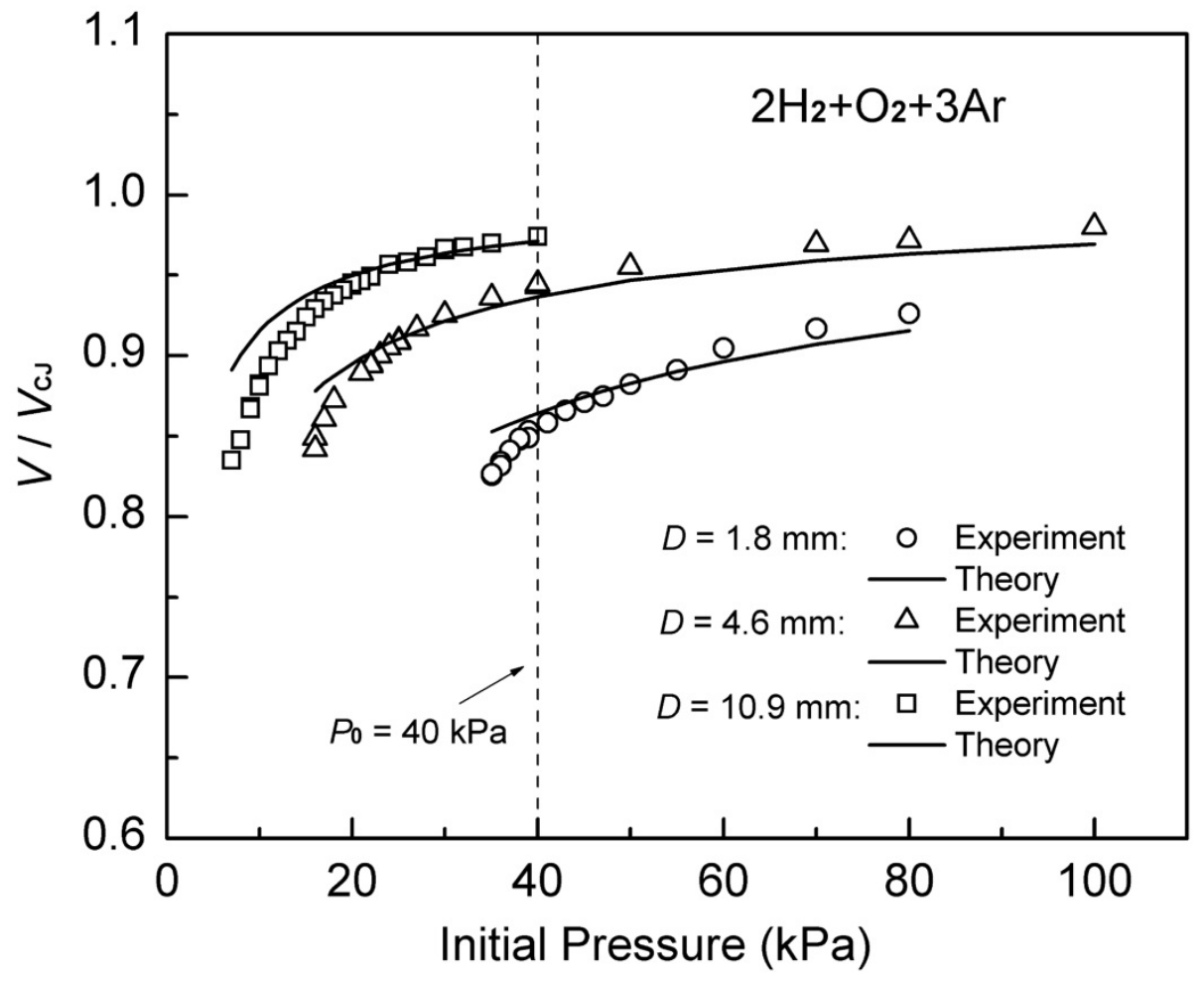

Fig. 4 


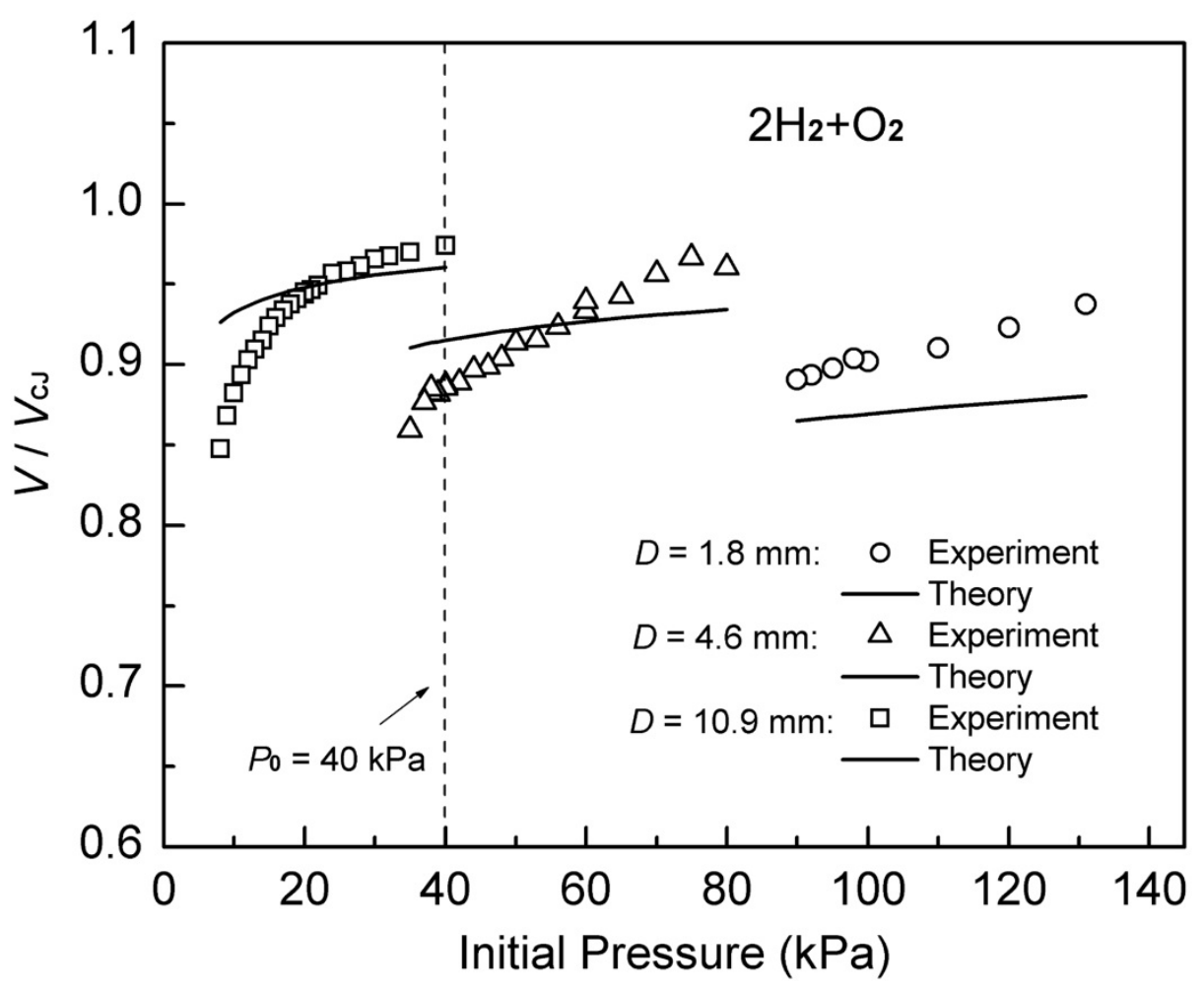

Fig. 5 


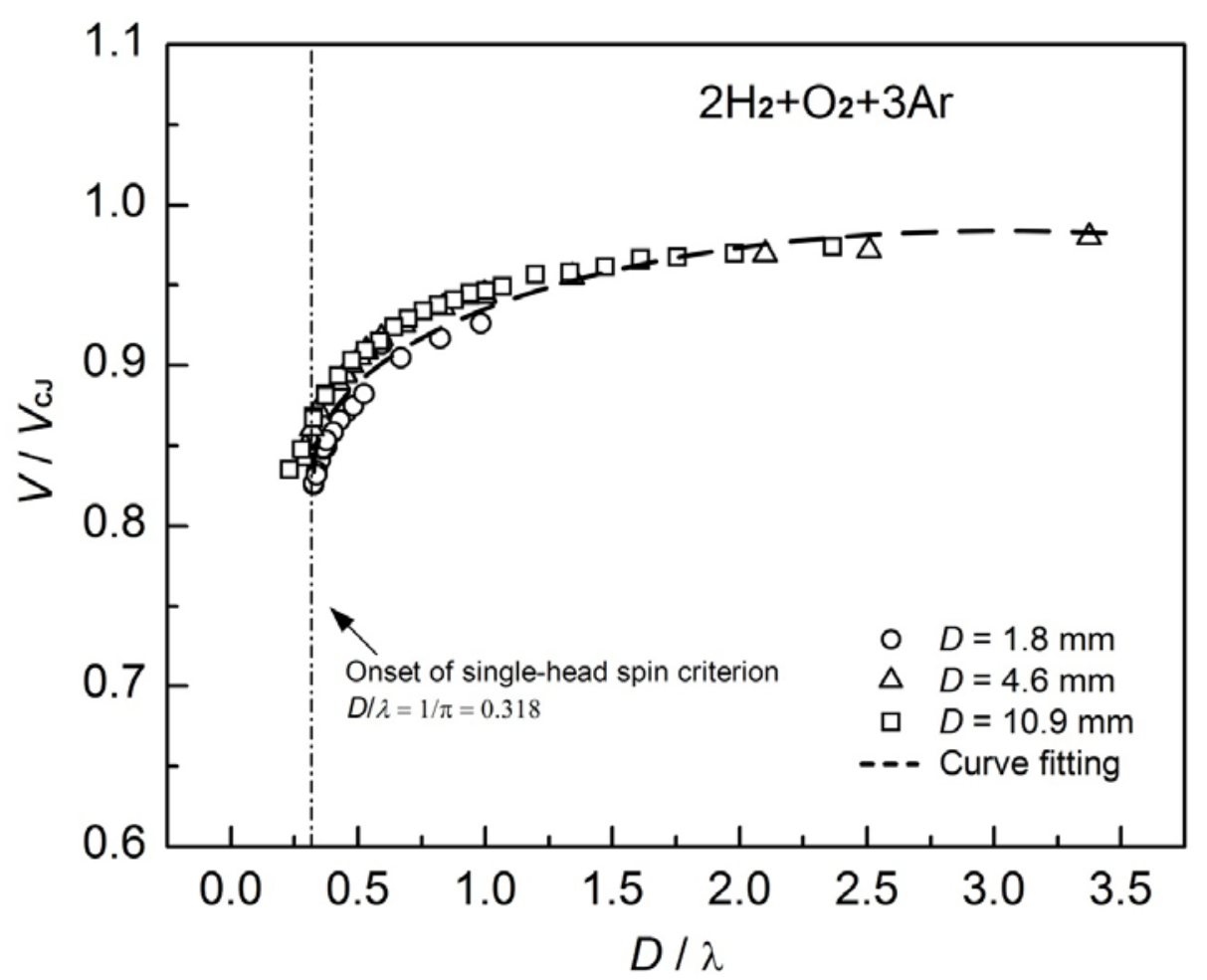

Fig. 6 




Fig. 7 